УДК 579.266:663

\author{
В. В. Коломоєць, І. Є. Соколова, О. А. Святун \\ Дніпропетровський національний університет ім. Олеся Гончара

\section{УЧАСТЬ МІКРООРГАНІЗМІВ У ПРОЦЕСАХ БІОДЕГРАДАЦІї ВІДХОДІВ}

Установлено, що для утилізації продуктів піролітичної деградації відходів можуть бути застосовані мікроорганізми. Вивчено вплив унесення мікроелементів у мікродозах на здатність виділених грунтових культур мікроорганізмів рости на бідних живильних середовищах, які моделюють співвідношення кінцевих продуктів піролізу. Показано позитивний вплив унесення $\mathrm{MnCl}_{2}, \mathrm{~K}_{2} \mathrm{HPO}_{4}$, $\mathrm{NH}_{4} \mathrm{NO}_{3}$, а також комплексу мікроелементів на здатність виділених мікроорганізмів накопичувати біомасу та асимілювати суб̆страт. Серед двох виділених і досліджених грунтових культур найперспективнішими є мікроорганізми роду Bacillus.

$$
\begin{gathered}
\text { В. В. Коломоец, И. Е. Соколова, О. А. Святун } \\
\text { Днепропетровский наииональный университет им. Олеся Гончара } \\
\text { УЧАСТИЕ МИКРООРГАНИЗМОВ } \\
\text { В ПРОЦЕССАХ БИОДЕГРАДАЦИИ ОТХОДОВ }
\end{gathered}
$$

Установлено, что для утилизации продуктов пиролитической деградации отходов могут быть использованы микроорганизмы. Изучено влияние внесения микроэлементов в микродозах на способность выделенных почвенных культур микроорганизмов расти на бедных питательных средах, моделирующих конечное соотношение продуктов пиролиза. Показано позитивное влияние внесения $\mathrm{MnCl}_{2}, \mathrm{~K}_{2} \mathrm{HPO}_{4}, \mathrm{NH}_{4} \mathrm{NO}_{3}$, а также комплекса микроэлементов на способность выделенных микроорганизмов накапливать биомассу и ассимилировать субстрат. Из двух выделенных и исследованных почвенных культур наиболее перспективными являются микроорганизмы рода Bacillus.

\author{
V. V. Kolomoets, I. E. Sokolova, O. A. Svjatun \\ Oles' Gonchar Dnipropetrovs'k National University \\ PARTICIPATION OF MICROORGANISMS \\ IN PROCESSES OF WASTE BIODEGRADATION
}

It is shown, that microorganisms can be used for utilisation of products of waste degradation. The influence of microelements small doses on the ability of secured cultures of soil microorganisms to grow on poor nutrient medium was studied. The cultures simulate the relationship of the end products of waste pyrolysis. The positive influence of $\mathrm{MnCl}_{2}, \mathrm{~K}_{2} \mathrm{HPO}_{4}, \mathrm{NH}_{4} \mathrm{NO}_{3}$ as well as the complex of microelements on the ability of secured microorganisms to accumulate the biomass and assimilate the substrate is shown. Among two secured and studied germ cultures the genus of-Bacillus is more promising.

\title{
Ветуп
}

На сьогодні проблема переробки та утилізації відходів у всьому світі стоїть дуже гостро. Це пов'язано як 3 об’ємами відходів, що все збільшуються, так і 3 недосконалістю методів їх переробки [3; 7; 9; 12]. Методи утилізації відходів, запропоновані на даному етапі розвитку промисловості, дуже різноманітні, проте не всі 
3 них можна назвати екологічно безпечними та економічно обгрунтованими, адже в результаті технологічних процесів деградації можуть утворюватися небезпечні кінцеві продукти, а також сполуки, які самі потребують подальшої утилізації [1; 4; 13; 14$]$. Останні десятиліття активно розроблялися нові технології деградації відходів. Виходячи 3 даних літератури, найефективнішими 3 них вважаються піроліз, рециклінг i мікробіологічна деструкція [2; 5; 6; 8; 15]. Саме тому актуальним став пошук мікроорганізмів, здатних накопичувати біомасу, використовуючи прості неорганічні сполуки 3 кінцевих продуктів деградації відходів як єдине джерело живлення. Мета даної роботи - пошук мікроорганізмів-хемоавтотрофів, здатних рости на бідних поживних середовищах, що моделюють кінцеві продукти піролізу, оптимізація середовищ їх культивування.

\section{Матеріал і методи досліджень}

Об'єкт досліджень - штами мікроорганізмів, виділені з гетерогенних грунтових та компостних культур. Культура № 1 - грампозитивні мікроорганізми роду Bacillus. Культура № 2 - грамнегативні палички Xanthobacter autotrophus. Ідентифікацію здійснювали відповідно визначника Берджі [10; 11]. Культивування мікроорганізмів проводили на синтетичних середовищах (співвідношення $C: N-10: 1$ ) наступного складу: $\mathrm{CaCO}_{3}-41,65$ г, $\left(\mathrm{NH}_{4}\right)_{2} \mathrm{SO}_{4}-4,165$ г, $\mathrm{K}_{2} \mathrm{HPO}_{4}-1,0$ г, $\mathrm{MgSO}_{4} * 7 \mathrm{H}_{2} \mathrm{O}-0,5$ г, $\mathrm{NaCl}-2$ г, $\mathrm{FeSO}_{4}-0,005$ г, дистильована вода - до 1 л. Склад середовища підібраний експериментально.

Щоб дослідити вплив унесення мікроелементів на здатність виділених культур мікроорганізмів рости на бідному синтетичному середовищі, використовували метод нефелометрії. Для перерахунку показників оптичної густини на біомасу (г/л) будували калібрувальну криву. У дослідженні використовували окремі мікроелементи (табл. 1), проводили їх комплексне внесення та контроль без внесення мікроелементів. Мікроелементи додавали у вказаних об'ємах до 10 мл основного живильного середовища, культивували досліджувані культури у термостаті за температури $+37^{\circ} \mathrm{C}$ протягом 10 діб.

Таблиия 1

Схема постановки експерименту з внесення мікроелементів

\begin{tabular}{|c|c|c|}
\hline Сполуки & Концентрація розчину, $\%$ & Об’єм, мл/10 мл \\
\hline $\mathrm{CaCl}_{2}$ & 10,00 & 0,20 \\
\hline $\mathrm{MgCl}_{2}$ & 5,60 & 0,10 \\
\hline $\mathrm{ZnSO}_{4}$ & 0,002 & 0,10 \\
\hline $\mathrm{MnCl}_{2}$ & 1,50 & 0,01 \\
\hline $\mathrm{NH}_{4} \mathrm{NO}_{3}$ & 9,50 & 0,01 \\
\hline $\mathrm{K}_{2} \mathrm{HPO}_{4}$ & 2,50 & 0,16 \\
\hline $\mathrm{NaOH}$ & $1 \mathrm{H}$ & 0,10 \\
\hline
\end{tabular}

\section{Результати та їх обговорення}

Для з’ясування впливу внесення мікроелементів на здатність виділених культур мікроорганізмів рости на бідному поживному середовищі проводили серію експериментів з метою визначити показники залишкової кількості $\mathrm{CaCO}_{3}$ (як джерела вуглецю) та накопичення біомаси мікроорганізмів.

Після десятиденного культивування у термостаті при $+37^{\circ} \mathrm{C}$ мікробні культури фільтрували. Фільтри висушували, визначали їх вагу, яка складалася із залишків 
неутилізованого карбонату кальцію та біомаси мікроорганізмів. Кількість неутилізованого $\mathrm{CaCO}_{3}$ визначали як різницю між загальною вагою фільтра та біомасою мікробів, визначеною за допомогою калібрувальної кривої. Мета даного експерименту - визначити здатність культур використовувати в процесі росту неорганічні джерела вуглецю $\left(\mathrm{CaCO}_{3}\right)$ (табл. 2).

Залишкова кількість $\mathrm{CaCO}_{3}$ (г/л) при культивуванні мікроорганізмів роду Bacillus та Xanthobacter autotrophus на бідному середовищі за присутності мікроелементів

\begin{tabular}{|c|c|c|}
\hline Сполуки & Мікроорганізми роду Bacillus & Xanthobacter autotrophus \\
\hline $\mathrm{CaCl}_{2}$ & $27,1 \pm 1,3$ & $26,2 \pm 1,3$ \\
\hline $\mathrm{MgCl}_{2}$ & $30,9 \pm 1,5$ & $29,2 \pm 1,5$ \\
\hline $\mathrm{ZnSO}_{4}$ & $22,9 \pm 1,1$ & $26,5 \pm 1,3$ \\
\hline $\mathrm{MnCl}_{2}$ & $13,1 \pm 0,7$ & $19,9 \pm 1,0$ \\
\hline $\mathrm{NH}_{4} \mathrm{NO}_{3}$ & $11,6 \pm 0,6$ & $22,6 \pm 1,1$ \\
\hline $\mathrm{K}_{2} \mathrm{HPO}_{4}$ & $24,0 \pm 1,2$ & $20,4 \pm 1,1$ \\
\hline $\mathrm{NaOH}$ & $15,9 \pm 0,6$ & $22,4 \pm 1,1$ \\
\hline Комплекс мікроелементів & $18,1 \pm 0,9$ & $28,9 \pm 1,4$ \\
\hline Контроль & $30,4 \pm 1,5$ & $37,4 \pm 1,8$ \\
\hline
\end{tabular}

Внесення мікроелементів не чинить значного впливу на здатність виділених культур утилізувати $\mathrm{CaCO}_{3}$ (див. табл. 2), проте певне підвищення здатності до асиміляції карбонату кальцію все ж виявлене при внесенні у мікрокількостях $\mathrm{NH}_{4} \mathrm{NO}_{3}, \mathrm{MnCl}_{2}$ та $\mathrm{NaOH}$ для мікроорганізмів роду Bacillus (культура № 1) та $\mathrm{MnCl}_{2}, \mathrm{~K}_{2} \mathrm{HPO}_{4}$ для Xanthobacter autotrophus (культура № 2). При цьому в середньому відмічалася майже однакова здатність до утилізації карбонату кальцію культурою № 1 та 2. Внесення окремих мікроелементів мало більший вплив на здатність до утилізації $\mathrm{CaCO}_{3}$, ніж внесення комплексу мікроелементів, що є більш економічним для оптимізації середовищ.

Одночасно 3 визначенням здатності утилізації $\mathrm{CaCO}_{3}$ визначали вплив унесення мікроелементів на ростові показники виділених культур. Це дослідження виконували за допомогою методу нефелометрії шляхом визначення оптичної густини у пробах відфільтрованої культуральної рідини. За допомогою побудованого калібрувального графіка визначено біомасу мікроорганізмів у культуральній рідині (табл. 3).

Табличя 3

Ростові показники накопичення біомаси мікроорганізмів роду Bacillus та Xanthobacter autotrophus за присутності мікроелементів

\begin{tabular}{|c|c|c|}
\hline Сполуки & Біомаса видів роду Bacillus, $\Gamma /$ $\times 10^{-3}$ & Біомаса Xanthobacter autotrophus, $г / \pi^{\times} \times 10^{-3}$ \\
\hline $\mathrm{CaCl}_{2}$ & $7,88 \pm 0,39$ & $5,03 \pm 0,25$ \\
\hline $\mathrm{MgCl}_{2}$ & $9,75 \pm 0,48$ & $5,10 \pm 0,25$ \\
\hline $\mathrm{ZnSO}_{4}$ & $8,13 \pm 0,40$ & $6,53 \pm 0,32$ \\
\hline $\mathrm{MnCl}_{2}$ & $10,63 \pm 0,53$ & $6,45 \pm 0,32$ \\
\hline $\mathrm{NH}_{4} \mathrm{NO}_{3}$ & $10,50 \pm 0,52$ & $6,68 \pm 0,33$ \\
\hline $\mathrm{K}_{2} \mathrm{HPO}_{4}$ & $12,25 \pm 0,61$ & $5,78 \pm 0,28$ \\
\hline $\mathrm{NaOH}$ & $8,50 \pm 0,42$ & $5,18 \pm 0,27$ \\
\hline Комплекс мікроелементів & $12,13 \pm 0,60$ & $4,20 \pm 0,21$ \\
\hline Контроль & $8,63 \pm 0,43$ & $3,75 \pm 0,18$ \\
\hline
\end{tabular}

При внесенні мікроелементів інтенсивність накопичення біомаси незначно відрізняється від контролю, проте внесення $\mathrm{K}_{2} \mathrm{HPO}_{4}, \mathrm{MnCl}_{2}$ та комплексу мікроелемен- 
тів для культури № 1 та $\mathrm{NH}_{4} \mathrm{NO}_{3}, \mathrm{MnCl}_{2}, \mathrm{~K}_{2} \mathrm{HPO}_{4}$ - для культури № 2 викликає незначну стимуляцію накопичення біомаси у культуральній рідині.

Співставлення отриманих результатів свідчить про те, що оптимальне співвідношення накопичення біомаси та утилізації $\mathrm{CaCO}_{3}$ для культури мікроорганізмів роду Bacillus спостерігається при використанні комплексу мікроелементів (збільшення приросту біомаси в 1,4 раза), крім того, достовірні показники отримані при внесенні таких сполук як $\mathrm{MnCl}_{2}$ (у 1,2 раза) та $\mathrm{NH}_{4} \mathrm{NO}_{3}$ (у 1,2 раза). Показники приросту біомаси здебільшого мало відрізнялися від контролю, проте здатність до асиміляції крейди значно варіювала.

\section{Висновки}

При аналізі співвідношення даних для культури Xanthobacter autotrophus показано, що оптимальне співвідношення накопичення біомаси та утилізації карбонату кальцію спостерігалося при внесенні у середовище культивування $\mathrm{MnCl}_{2}, \mathrm{~K}_{2} \mathrm{HPO}_{4}, \mathrm{NH}_{4} \mathrm{NO}_{3}$. Збільшення приросту біомаси спостерігали при внесенні $\mathrm{NH}_{4} \mathrm{NO}_{3}$ (у 1,78 раза), $\mathrm{ZnSO}_{4}$ (у 1,74 раза) та $\mathrm{MnCl}_{2}$ (у 1,72 раза). Використання внесення комплексу мікроелементів для культури № 2 не дало значних позитивних результатів порівняно 3 контрольною пробою. Аналіз накопичення біомаси показав, що внесення мікроелементів для Xanthobacter autotrophus мало більше значення, ніж для мікроорганізмів роду Bacillus, проте вихід біомаси останньої культури був спочатку в 2,3 раза вищий, ніж у культури $X$. autotrophus. Це свідчить про більшу економічну перспективність першої культури.

Співставлення отриманих даних за накопиченням біомаси, утилізацією $\mathrm{CaCO}_{3}$ та необхідністю внесення додаткових мікроелементів свідчить, що мікроорганізми роду Bacillus володіють здатністю до росту на бідних середовищах і перспективніші для використання з метою утилізації неорганічних відходів.

\section{Бібліографічні посилання}

1. Алборов И. Д. Исследование биохимических процессов, происходящих на полигонах твердых бытовых отходов / И. Д. Алборов, С. В. Степанова // Вестник МАНЭБ. - 2002. - Т. 7 , № 9 (57). - C. 32-34.

2. Анышаков А. С. Переработка твердых бытовых отходов методом высокотемпературной (плазменной) газификации / А. С. Аньшаков, В. С. Чередниченко // Утилизация отходов большого города. Тез. докл. научн.-практ. семинара. - М. : ВИМИ, 1993. - С. 16-17.

3. Базилевич Л. М. Способи боротьби із забрудненням навколишнього середовища / Л. М. Базилевич, В. Б. Риза, Ю. А. Змитрук // Безпека життєдіяльності. - 2005. - № 2. - С. 13-15.

4. Бикбау М. Я. Новые подходы к переработке ТБО // Экол. вестн. России. - 2006. - № 12. - С. 48-51.

5. Биодеградация твердых бытовых отходов в естественных и искусственных экосистемах / И. Н. Лыков, С. А. Сафронова, М. И. Морозенко и др. // Прогрессивные технологии, конструкции и системы в приборо- и машиностроении. Матер. Всерос. научн.-техн. конф. - М. : МГТУ им. Н. Э. Баумана, 2005. - Т. 1. - С. 203-206.

6. Биотехнология переработки органических отходов и экология / И. И. Гудилин, А. Ф. Кондратов, А. А. Чичин и др. - Новосибирск: Кн. изд-во, 1999. - 391 с.

7. Богоявленский Р. Г. Мировые тенденции в области современных технологий утилизации твердых промышленных и бытовых отходов / Р. Г. Богоявленский, В. А. Рыжов // ЭКОС. 2000. - T. 1, № 8-12. - C. 42-51.

8. Волчатова И. В. Научные основы применения биотехнологии для утилизации органических отходов природного происхождения / И. В. Волчатова, С. А. Медведева, Л. А. Беловежец // Матер. IV съезда Общества биотехнологов России им. Ю. А. Овчинникова. - Пущино, 2006. - С. 39-40.

9. Дюдин Ю. К. Современные тенденции в развитии индустрии переработки твердых бытовых отходов / Ю. К. Дюдин, С. И. Капитонов // Вестник Гефеста. - 2006. - № 3. - С. $20-25$. 
10. Краткий определитель бактерий Берги / Под ред. Д. Хоулта. - М. : Мир, 1980. - 495 с.

11. Определитель бактерий Берджи / Под ред. Д. Хоулта, Н. Крига, П. Снита и др. - М. : Мир, 1997. - T. 1. $-430 \mathrm{c}$.

12. Экологическая биотехнология / Под ред. К. Ф. Форстера, Д. А. Д. Вейза. - Л. : Химия, 1990. - 384 с.

13. Hasselriis F. Оценка реальных выбросов от устройств для сжигания муниципальных, медицинских и опасных отходов // Научн. и техн. аспекты охраны окруж. среды: Обзорная информация / ВИНИТИ. -2000 . - № 6. - С. 78-87.

14. Kimbara K. Disposal of industrial waste // Japan Railway \& Transport Review. - 1998. - N 17. - P. 17-19.

15. Kuhner M. Planenkompostierung - Kompostierung unter semipermeable Planenabdeckungen // Bioabfallkompostierung: Neue Entwicklungen und Losungsmoglichkeiten zur Reduzierung von Geruchsemissionen. - Wiesbaden : Hess. Landesamt Umwelt und Geol., 2001. - P. 29-37.

Надійшла до редколегії 30.11.2009 